per cent of the injury fatalities but the share of life years lost amounts to 35 per cent, losing on average 32 years of life per fatality. For unintentional injuries, road traffic accidents historically have been the leading cause for loss of life years but since 2008 poisonings cause the highest loss. In 2014, also falls caused a higher number of life years lost than did road traffic accidents.

There are large differences in the average number of life years lost in different injury types. While the average fall fatality in 2014 caused a loss of 9 years, road traffic fatalities lost on average 32 years of life and poisoning fatalities on average 40 years. Conclusions Using potential years of life lost due to injuries as a complement to the number of deaths will change the picture of which types of accidents place the heaviest burden on society, allowing a more nuanced description of the burden of injury fatalities.

\section{COST OF CHILD AND ADOLESCENT INJURY IN THE UNITED STATES: BY AGE GROUP, CAUSE, AND PAYER}

Rebecca Spicer, Bruce Lawrence, Ted Miller. Pacific Institute for Research and Evaluation, Calverton, MD, USA

\subsection{6/injuryprev-2016-042156.112}

Background In 2012 in the United States, 13,454 children and adolescents died due to injury and another 9 million visited the emergency department or were hospitalised. However, incidence tells only part of the story. Costs are a better measure of burden by accounting for multiple injury consequences - death, severity, disability - in a single unit of measurement.

Methods We apply an established injury cost model to the Healthcare Cost and Utilisation Program (HCUP) sample-based emergency department and inpatient datasets and the U.S. Multiple Cause of Death file. In addition to medical and work loss costs, we take a societal perspective by including the estimated cost of quality of life and pain and suffering.

Results Injuries (fatal, hospitalised and ED-treated) to 0 through 19 year-olds in 2012 resulted in an estimated $\$ 92$ billion in medical and work loss costs and an additional $\$ 502$ billion in quality of life losses. Nonfatal injuries account for the majority $(83 \%)$ of these costs. Adolescents (ages 15-19) account for 29\% of the injuries but $37 \%$ of the costs. Falls and struck by/against injuries contribute to $51 \%$ of nonfatal injury costs and are the leading causes in all age groups. Assault-related injuries rank $5^{\text {th }}, 9^{\text {th }}$, and $4^{\text {th }}$ among 0-4, 10-14, and 15-19 year-olds, respectively. Selfharm ranks $9^{\text {th }}$ among 15-19 year-olds. Government costs are high with Medicaid paying for $43 \%$ of medical costs. Proportion paid by Medicaid is higher among 0-4 year-olds (54\%) and among assault (60\%), and unintentional firearm (62\%), bite and sting (56\%), and hot object/substance (55\%) injuries. The most severe and debilitating injuries will result in higher costs. Among nonfatal injuries, near-drownings are the most costly. Trafficrelated injuries are also among the most severe with pedestrian, motorcycle, and pedalcyclist injuries ranked \#2, \#4, and \#5 in mean injury cost.

Conclusions Cost data support priority-setting and intervention selection. Effectively addressing falls, struck by/against injuries, and assaults will reduce the burden of injury in the United States.

\section{ROAD TRAFFIC INJURY COST ESTIMATION BY WILLINGNESS TO PAY METHOD}

Elaheh Ainy, Hamid Soori. Safety Promotion and Injury Prevention Research Centre of Shahid Beheshti University of Medical Sciences

\subsection{6/injuryprev-2016-042156.113}

Background There are different methods for injury cost calculation. This study is the first ever one using the willingness (WTP) to pay method a middle-income country such as Iran in 2013 to calculate the cost of road traffic injuries (RTIs).

Methods In a Cost Analysis Method study on costs resulting from RTIs, 846 people per road user were randomly selected and investigated. The research questionnaire was prepared based on the standard for WTP method; Contingent value (CV), stated preference (SP), revealed preference (RP) model considering perceived risks. The collected data were analysed after their strict control. Final analysis of WTP was carried out using Weibull model and Bayesian method.

Results Mean age of the subjects was $33.4 \pm 9.9$ years old. Mean WTP was 87 among these road users. Statistical value of life for one death and one injury cases were estimated 19,713,584,906 IRR and 2,412,582,500 IRR respectively. In sum, 20408 death and 318,802 injury cases amounted to $1,171,450,232,238,648$ IRR equivalents to $39,048,341,074 \$$. Moreover in 2013, costs of RTIs constituted $6.46 \%$ of gross national income, which was $604,300,000,000$ \$. Findings obtained from Weibull model and Bayesian model showed that WTP had a significant relationship with age, gender, education, monthly income.

Conclusions Costs of traffic injuries were much higher than the global statistics. If policy making and resource allocation are made based on the scientific pieces of evidence, an enormous amount of capital can be saved through reducing death and injury rates. This method seems to be more precise method to traffic injury cost estimation than human capital method.

\section{PREVALENCE OF DISABILITY IN A DISTRICT OF BANGLADESH}

${ }^{1}$ Mohammad Moniruzzaman, ${ }^{1} \mathrm{M}$ Mostafa Zaman, ${ }^{2}$ Saidur Rahman Mashreky, ${ }^{2}$ AKM Fazlur Rahman. 'WHO Country Office for Bangladesh, Bangladesh; ${ }^{2}$ Centre for Injury Prevention and Research Bangladesh, Bangladesh

\subsection{6/injuryprev-2016-042156.114}

Background Data on disability among Bangladeshi people are suboptimal, extremely variable, methodologically inconsistent, and not precisely known. Therefore, we conducted a comprehensive survey on disability to determine prevalence and distribution of cause specific disability among residents of a district in Bangladesh.

Methods The survey was conducted in Manikganj, a typical district in Bangladesh, in 2009. Data were collected from 37,030 individuals of all ages. Samples were drawn out of 8,905 households from urban and rural areas proportionate to population size. Three sets of interviewer administered questionnaires were used separately for 0-1 years, 2-10 years, and 11 years and above age groups to collect data. For the age groups $0-1$ years 